\title{
PENGEMBANGAN APLIKASI ANDROID 'AYO CUCI TANGAN' UNTUK MENGAJARKAN KEBERSIHAN ANGGOTA TUBUH PADA MUATAN PELAJARAN IPA DI SEKOLAH DASAR
}

\author{
Muyassaroh $^{1^{*}}$, Reno Nurdiyanto ${ }^{2}$, Laifa Rahmawati ${ }^{3}$
}

${ }^{1}$ SLB Negeri 2 Yogyakarta, Indonesia, ${ }^{2,3}$ Universitas Negeri Yogyakarta, Indonesia *Corresponding Author: muyas1909@gmail.com

\begin{tabular}{|c|c|}
\hline Info Artikel & Abstract. This study aims to (1) produce an android application 'let's wash your hands' to \\
\hline $\begin{array}{l}\text { Sejarah Artikel: } \\
\text { Diterima: } 22 / 12 / 2021 \\
\text { Direvisi : } 03 / 01 / 2022 \\
\text { Disetujui:05/01/2022 }\end{array}$ & $\begin{array}{l}\text { teach body hygiene in science lesson content in elementary schools (2) determine the value } \\
\text { of product feasibility. This type of research is research and development. This study uses a } \\
4 d \text { model. This model consists of four steps; (1) define, (2) design, (3) development, and } \\
\text { (4) disseminate. Product validation is calculated based on the results of expert }\end{array}$ \\
\hline $\begin{array}{l}\text { Keywords: } \\
\text { Android Application, } \\
\text { hand washing, science, } \\
\text { elementary school }\end{array}$ & $\begin{array}{l}\text { with the topic of 'washing hands' (2) the media developed has a good feasibility value. } \\
\text { Based on these findings, it shows that the 'let's wash your hands' android application is } \\
\text { feasible to use in learning. }\end{array}$ \\
\hline $\begin{array}{l}\text { Kata Kunci: } \\
\text { Aplikasi android, cuci } \\
\text { tangan, IPA, SD }\end{array}$ & $\begin{array}{l}\text { Abstrak. Penelitian ini bertujuan untuk (1) menghasilkan aplikasi android 'ayo cuci } \\
\text { tangan' untuk mengajarkan kebersihan anggota tubuh pada muatan pelajaran IPA di } \\
\text { Sekolah Dasar (2) menentukan nilai kelayakan produk. Jenis penelitian ini adalah } \\
\text { penelitian dan pengembangan. Penelitian ini menggunakan model 4d. Model ini terdiri } \\
\text { dari empat langkah; (1) define, (2) design, (3) development, dan (4) disseminate. Validasi } \\
\text { produk dihitung berdasarkan hasil penilaian ahli. Hasil dari penelitian dan pengembangan } \\
\text { ini adalah (1) aplikasi android dengan topik 'cuci tangan' (2) media yang dikembangkan } \\
\text { memiliki nilai kelayakan yang baik. Berdasarkan temuan ini, menunjukkan bahwa } \\
\text { aplikasi android 'ayo cuci tangan' layak digunakan dalam pembelajaran. }\end{array}$ \\
\hline \multicolumn{2}{|c|}{$\begin{array}{l}\text { How to Cite: Muyassaroh, M., Nurdiyanto, R., \& Rahmawati, R. (2022). PENGEMBANGAN APLIKASI ANDROID 'AYO } \\
\text { CUCI TANGAN' UNTUK MENGAJARKAN KEBERSIHAN ANGGOTA TUBUH PADA MUATAN PELAJARAN IPA DI } \\
\text { SEKOLAH DASAR. Prima Magistra: Jurnal Ilmiah Kependidikan, 3(1), 131-138. https://doi.org/10.37478/jpm.v3i1.1508 }\end{array}$} \\
\hline Alamat korespondensi: & Penerbit: \\
\hline \multicolumn{2}{|c|}{$\begin{array}{l}\text { J1. Panembahan Senopati No.46, Prawirodirjan, Kec. } \\
\text { Gondomanan, Kota Yogyakarta, Daerah Istimewa } \\
\text { Yogyakarta 55121@ muyas1909@gmail.com }\end{array}$} \\
\hline
\end{tabular}




\section{PENDAHULUAN}

Kelayakan hidup manusia tidak dapat lepas dari faktor kesehatan. Kesehatan berupakan kunci dalam hidup sejahtera. Kesehatan dapat tercapai dengan penerapan perilaku hidup bersih dan sehat (PHBS). Sekolah merupakan salah satu tempat pelaksanaan program PHBS oleh pemerintah (Depkes RI, 2011).

Program PHBS paling sederhana namun penting dilaksanakan yaitu kegiatan mencuci tangan. Kegiatan mencuci tangan juga merupakan bagian dari upaya untuk menghindari penularan beragam penyakit (Risnawaty, 2016; Parasyanti et al., 2020) dan juga COVID-19. Banyak anak SD yang memahami mencuci tangan serupa dengan kegiatan membasahi tangan (Saputri \& Suryati, 2019). Mencuci tangan yang benar memiliki tujuh langkah dan dilakukan dengan menggunakan sabun. Cuci tangan pakai sabun (CTPS) merupakan kegiatan membersihkan kotoran dan debu dari permukaan kulit, kuku, dan jemari pada kedua tangan dengan menggunakan sabun dan air mengalir dengan tujuan mengurangi kuantitas mikroorganisme penyebab penyakit (Desiyanto \& Djannah, 2013).

Kegiatan mencuci tangan merupakan bagian dari menjaga keseharan tubuh. Pengenalan anggota tubuh dan cara menjaga kesehatan termasuk dalam muatan pelajaran IPA pada mata pelajaran tematik di kelas I Sekolah Dasar. Pembelajaran mengenai mencuci tangan telah banyak disampaikan dengan beragam media pembelajaran. Pembelajaran cuci tangan dengan media poster (Sari, 2021; Andriani, 2020), media komik (Ridha et al., 2016), menyanyi (Aminingsih, 2021; Juliawan, 2019; Rahmawati et al., 2020; Suwanti \& Krisbiantoro, 2019), senam (Azizah \& Masistoh, 2018; Ashari et al., 2020; Indrayani et al., 2019; Zurrahmi et al., 2021), permainan (Andayani, 2016; Azizah et al., 2015; Nurhidayati \& Hilal, 2018; Sutriyanto et al., 2016), audio visual atau video (Rahmawati et al.,2015; Amalia, 2019; Fadiah et al., 2019; Saputri \& Suryati, 2019; Parasyanti et al., 2020).
Media pembelajaran cuci tangan berbasis aplikasi android belum dikembangkan banyak orang. Pengembangan media ini dinilai penting untuk mengikuti perkembangan jaman dan kegemaran siswa dengan teknologi pada gawai. Hal inilah yang menjadi latar belakang pengembangan aplikasi andorid 'ayo cuci tangan' untuk mengajarkan kebersihan anggota tubuh pada muatan pelajaran IPA di Sekolah Dasar.

\section{METODE PENELITIAN}

Pengembangan aplikasi andorid 'ayo cuci tangan' termasuk dalam jenis penelitian pengembangan. Prosedur pengembangan pada penelitian ini mengacu pada tahapan model pengembangan 4D Model. Tahapan pada model ini meliputi kegiatan Define untuk pendefinisian, Design untuk perancangan, Develop untuk pengembangan, dan Disseminate untuk penyebaran. Validasi produk pengembangan dilakukan oleh dua orang validator. Validasi meliputi aspek kelayakan isi, penyajian, bahasa, kegrafikan, dan kesehatan.

\section{HASIL DAN PEMBAHASAN}

\section{Pendefinisian (Define)}

Tahap pendefinisian peneliti menganalisis kebutuhan mengenai karakteristik peserta didik, tujuan pembelajaran, permasalahan ketika pembelajaran materi, media pembelajaran yang digunakan, kurikulum dan silabus yang digunakan. Media yang sering digunakan dalam daring berupa video pembelajaran dan materi.

\section{Perancangan (Design)}

Tahap perancangan terdiri dari dua instrumen yang dirancang yaitu instrumen penelitian dan instrumen pembelajaran. Instrumen penelitian meliputi angket validasi ahli dan praktisi untuk mengukur kelayakan media pembelajaran yang telah dibuat. Peneiti membuat rancangan media aplikasi berdasarkan analisis kebutuhuan yang telah terlaksana. Fokus pada permasalahan penelitian ini yaitu materi cara mencuci tangan.

Peneliti membuat flowchart untuk mempermudah proses pengembangan dan kerangka aplikasi. Flowchart dikembangkan 
Muyassaroh, Reno Nurdiyanto, Laifa Rahmawati

Pengembangan Aplikasi Android ‘Ayo Cuci Tangan’ untuk Mengajarkan Kebersihan Anggota Tubuh pada Muatan Pelajaran IPA di Sekolah Dasar

Prima Magistra: Jurnal Ilmiah Kependidikan Volume 3, Nomor 1, Januari 2022, hal 131-138

lagi menjadi berbagai sketsa gambar sementara. Aplikasi android 'Ayo Cuci Tangan' dikembangkan menggunakan aplikasi seperti Unity 3D, Visual Studio Code, CorelDraw hingga powerpoint. Coreldraw digunakan untuk membuat gambar ilustrasi, tombol-tombol dan asset untuk menggambar.

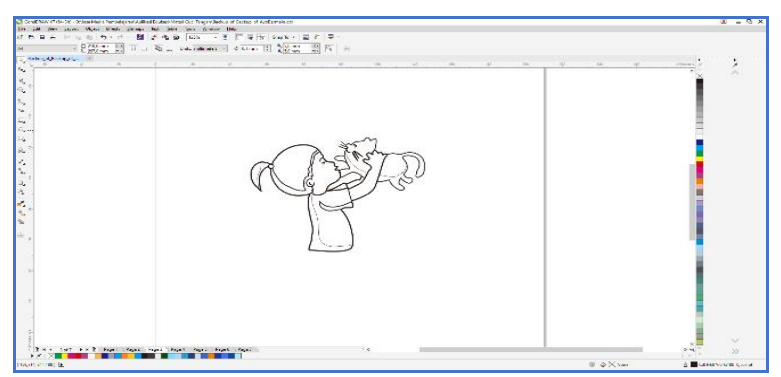

Gambar 1. Perancangan tampilan menggunakan CorelDraw X7

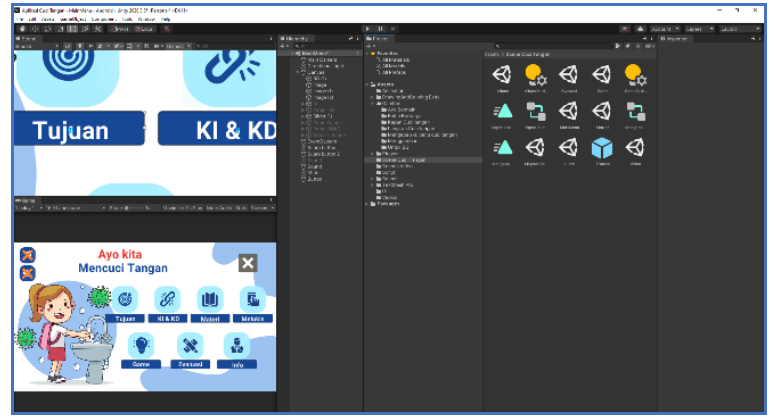

Gambar 2. Perancangan aplikasi menggunakan software Unity 3D

Setelah asset dan gambar terbuat, peneliti menggunakan Unity 3D untuk menggabungkan seluruh asset menjadi sebuah aplikasi. Pengembang membuat kode pemrograman komputer agar lebih interaktif menggunakan Visual Studio Code. Kode tersebut dapat menjalankan berbagai fitur seperti musik, menggambar, permainan hingga kuis. Bahasa yang digunakan dalam pemrograman Unity yaitu C\#.

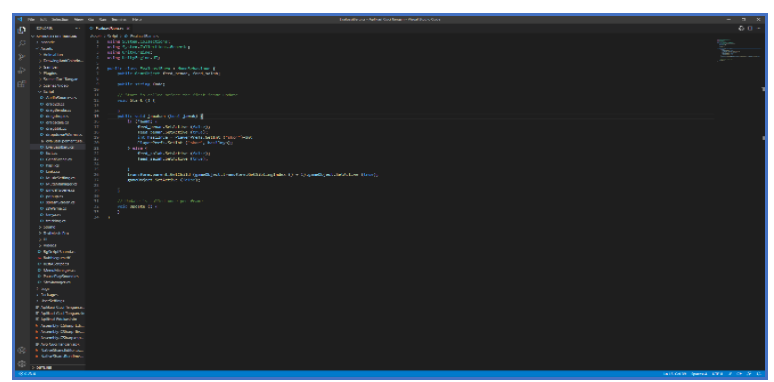

Gambar 3. Memberi instruksi pada aplikasi dengan bahasa C\# di VS Code

\section{Pengembangan (Develop)}

Pengembangan dilakukan dengan melakukan validasi dan penilaian oleh validator ahli dan praktisi. Aspek yang dinilai untuk mengukur kelayakan media yang telah dibuat yaitu kelayakan isi, kelayakan penyajian, kelayakan bahasa, komponen kegrafikan, dan komponen kesehatan. Validasi produk aplikasi dilakukan dengan cara kuisioner. Hasil validasi terebut digunakan untuk mengukur kelayakan dan memperbaiki produk.

\section{Penyebaran (Desiminate)}

Diseminasi dilakukan dengan menyebarkan aplikasi kepada rekan guru dan dosen. Peneliti juga membuatkan hak kekayaan intelektual atas produk yang telah dibuat dan diuji kelayakannya.

Aplikasi android "Ayo Cuci Tangan" merupakan aplikasi untuk mengajarkan peserta didik dalam bercuci tangan. Terdapat beberapa fitur menu pada aplikasi ini.

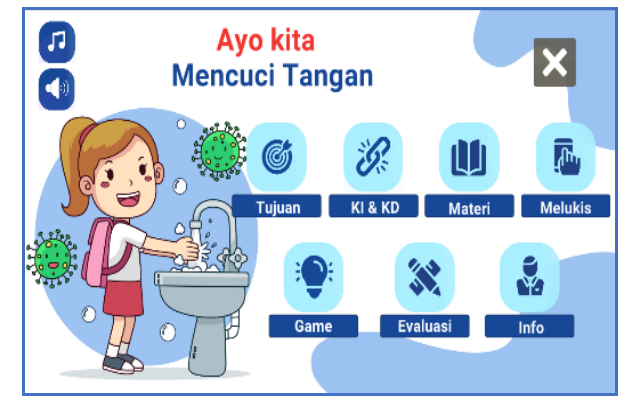

Gambar 4. Tampilan menu utama pada aplikasi

Tampilan fitur menu utama ditunjukkan pada Gambar 4. Menu utama berisi berbagai tombol untuk menu pilihan, pengaturan suara dan tombol keluar.

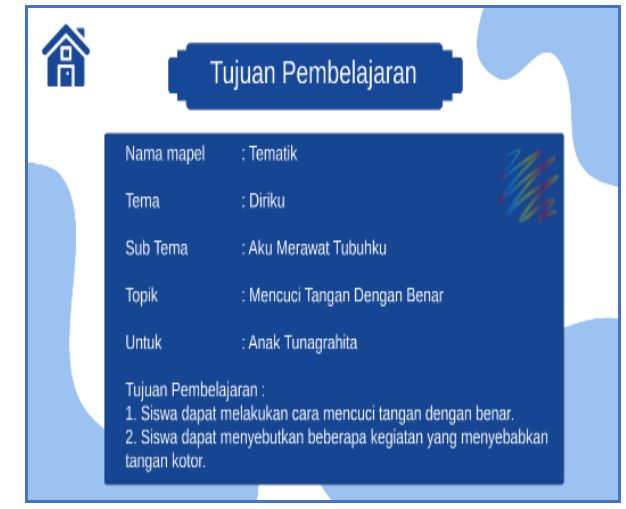

Gambar 5. Tujuan pembelajaran pada aplikasi 


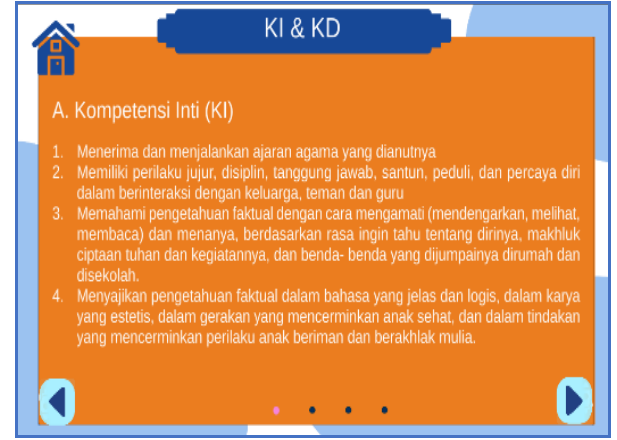

Gambar 6. Tampilan kompetensi inti dan kompetensi dasar

Tampilan fitur tujuan pembelajaran ditunjukkan pada Gambar 5 dan tampilan fitur KI KD ditunjukan pada Gambar 6. Kedua fitur ini berisi informasi mengenai tujuan pelajaran dan KI KD dari aplikasi ini. Selain itu juga berisi informasi tentang mata pelajaran, tema, topik dan sasaran pengguna.

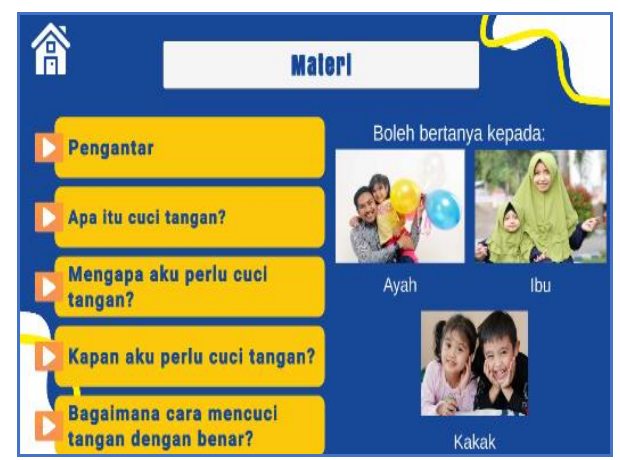

Gambar 4. Materi pada aplikasi "Ayo Cuci Tangan"

Tampilan fitur materi ditunjukkan pada Gambar 7. Materi berisi mengenai pengantar, pengertian cuci tangan, alasan mencuci tangan, waktu mencuci tangan, dan bagaimana mencuci tangan dengan baik dan benar. Pada menu materi terdapat saran untuk peserta didik agar belajar didampingi oleh kakak,ayah,atau ibu.

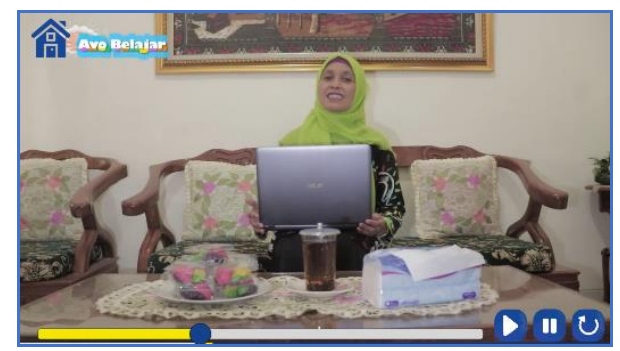

Gambar 5. Pemutaran video ajakan

Aplikasi ini juga dilengkapi dengan video singkat cerita tentang pentingnya mencuci tangan dan tata cara mencuci tangan dengan benar. Tampilan video pada aplikasi ditunjukkan pada Gambar 8. Peserta didik diberikan video mengenai pengantar yang mana guru menjelaskan materi cuci tangan disertai lagu dan animasi menarik.

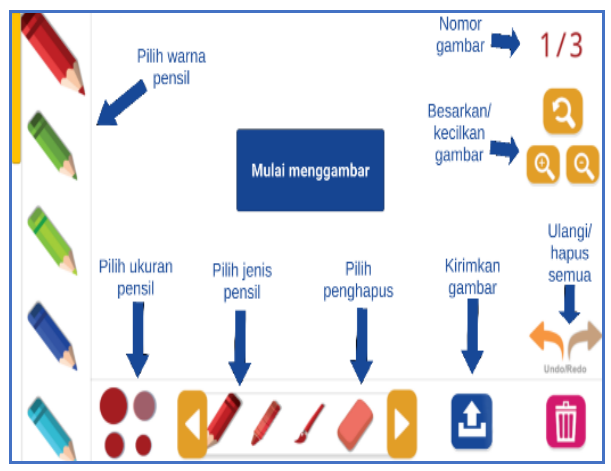

Gambar 6. Petunjuk melukis pada aplikasi

Aplikasi ini juga dilengkapi dengan game melukis. Tampilan petunjuk game mewarnai pada aplikasi ditunjukkan pada Gambar 9. Peserta didik diberi keleluasaan untuk aktif secara psikomotorik untuk melukis hal yang berkaitan dengan cuci tangan. Terdapat pilihan berbagai warna pensil dan ukuran pensil yang dapat digunakan. Jika telah selesai, peserta didik dapat mengirimkan gambar yang telah dihasilkan ke pihak guru. Peserta didik juga dapat menghapus gambar, mengulangi langkah sebelumnya ataupun setelahnya, memperbesar/memperkecil gambar dan memilih berbagai pensil/kuas sesuai dengan pola yang telah tersedia.

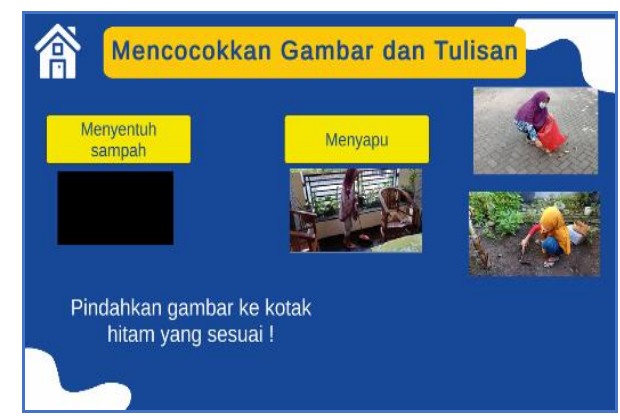

Gambar 7. Permainan dalam aplikasi

Aplikasi ini juga dilengkapi dengan permainan mencocokkan gambar yang tampilannya ditunjukkan pada Gambar 10. Peserta didik diberikan tantangan untuk memainkan permainan cocok gambar. Terdapat beberapa gambar aktivitas sehari 
Muyassaroh, Reno Nurdiyanto, Laifa Rahmawati

Pengembangan Aplikasi Android ‘Ayo Cuci Tangan’ untuk Mengajarkan Kebersihan Anggota Tubuh pada Muatan Pelajaran IPA di Sekolah Dasar

Prima Magistra: Jurnal Ilmiah Kependidikan Volume 3, Nomor 1, Januari 2022, hal 131-138

hari yang harus diletakan pada penanda yang telah dibuat.

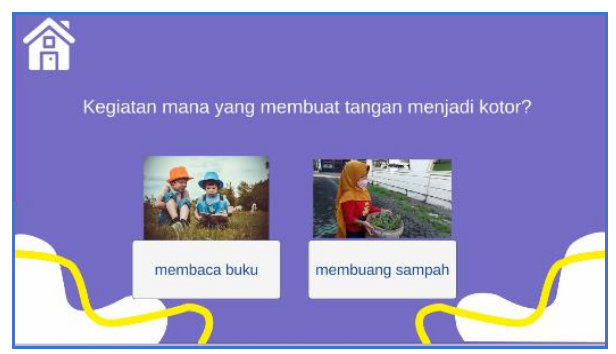

Gambar 8. Evaluasi pembelajaran pada aplikasi

Setelah menyelesaikan semua tantangan pembelajaran pada aplikasi, peserta didik dapat membuka evaluasi untuk mengetahui hasil belajar peserta didik. Evaluasi berbentuk pilihan ganda dengan dua pilihan disertai gambar seperti yang ditunjukkan pada Gambar 11.. Hal tersebut cocok untuk anak kelas 1 SD yang masih dalam tataran belajar membaca. Ketika peserta didik menjawab soal, akan ada interaksi audio-visual sebagai umpan balik.

Pada aplikasi ini juga terdapat informasi tambahan materi ini pembelajaran. Informasi yang juga disediakan pada aplikasi yaitu pengembang aplikasi, daftar pustaka dan sumber konten gambar maupun musik.

\section{Kelayakan Aplikasi "Ayo Cuci Tangan"}

Tingkat kelayakan aplikasi "Ayo Cuci Tangan" dilakukan dengan menganalisis hasil kuisioner angket validasi. Angket tersebut digunakan untuk memperbaiki dan meningkatkan kualitas instrumen yang telah dikembangkan. Komponen yang dinilai pada instrumen meliputi kelayakan isi, kelayakan penyajian, kelayakan bahasa, komponen kegrafikan pada aplikasi dan komponen materi kesehatan.

Tabel 1. Perhitungan data kelayakan isi

\begin{tabular}{llll}
\hline No & Komponen & Skor & Kategori \\
\hline 1 & $\begin{array}{l}\text { Kesesuaian uraian } \\
\text { materi dengan }\end{array}$ & Sangat baik \\
& $\begin{array}{l}\text { standar KI \& KD } \\
2\end{array}$ & $\begin{array}{l}\text { Keakuratan materi } \\
\text { Materi pendukung }\end{array}$ & 4,56 \\
pengembang & Sangat baik \\
& & \\
berpikir & & \\
\hline Total & 4,6 & Sangat baik \\
\hline
\end{tabular}

Hasil perhitungan menunjukkan isi dari aplikasi "Ayo cuci tangan" sudah sangat baik untuk digunakan dalam pembelajaran. Materi yang tersedia pada aplikasi sudah mencakup kompetensi dasar IPA, PPKn, Bahasa Indonesia, dan SBPD yang harus dikuasai peserta didik.

Tabel 2. Perhitungan data kelayakan penyajian

\begin{tabular}{llll}
\hline No & Komponen & Skor & Kategori \\
\hline 1 & Teknik penyajian & 4,67 & Sangat baik \\
2 & $\begin{array}{l}\text { Penyajian } \\
\text { pembelajaran }\end{array}$ & 4,83 & Sangat baik \\
3 & $\begin{array}{l}\text { Kelengkapan } \\
\text { penyajian }\end{array}$ & 4,75 & Sangat baik \\
\hline Total & 4,75 & Sangat baik \\
\hline
\end{tabular}

Berdasarkan perhitungan, validator menilai bahwa penyajian materi yang tertera pada aplikasi sangat baik untuk digunakan oleh siswa. Penyajian konsep hingga kelengkapannya telah disesuaikan dengan kebutuhan siswa kelas 1 SD.

Tabel 3. Perhitungan data kelayakan bahasa

\begin{tabular}{llll}
\hline No & Komponen & Skor & Kategori \\
\hline 1 & $\begin{array}{l}\text { Kesesuaian dengan } \\
\text { tingkat }\end{array}$ & S,75 \\
& $\begin{array}{l}\text { perkembangan } \\
\text { peserta didik }\end{array}$ & \\
2 & $\begin{array}{l}\text { Komunikatif } \\
3\end{array}$ & 4,5 & Sangat baik \\
& $\begin{array}{l}\text { Keruntutan dan } \\
\text { kesatuan gagasan }\end{array}$ & Sangat baik \\
\hline Total & 4,57 & Sangat baik \\
\hline
\end{tabular}

Dari hasil perhitungan, bahasa yang tertera pada aplikasi dinilai sangat baik untuk pemahaman tiap kata oleh tingkatan anak SD.

Tabel 4. Perhitungan data kelayakan kegrafikan

\begin{tabular}{|c|c|c|c|}
\hline No & Komponen & Skor & Kategori \\
\hline 1 & $\begin{array}{l}\text { Desain } \\
\text { aplikasi }\end{array}$ & 4,75 & Sangat baik \\
\hline 2 & Desain isi aplikasi & 4,75 & Sangat baik \\
\hline \multicolumn{2}{|c|}{ Total } & 4,75 & Sangat baik \\
\hline
\end{tabular}

Menunjukkan bahwa validator menilai grafik atau tampilan pada aplikasi sangat layak untuk menunjang pembelajaran di kelas.

Tabel 5. Perhitungan komponen kesehatan

\begin{tabular}{llll}
\hline No & Komponen & Skor & Kategori \\
\hline $\begin{array}{l}\text { Komponen } \\
\text { kesehatan }\end{array}$ & 5 & Sangat baik \\
\hline Total & 5 & Sangat baik \\
\hline
\end{tabular}

Dari segi komponen kesehatan, menunjukkan aplikasi layak untuk 
Muyassaroh, Reno Nurdiyanto, Laifa Rahmawati

Pengembangan Aplikasi Android 'Ayo Cuci Tangan' untuk Mengajarkan Kebersihan Anggota Tubuh pada Muatan Pelajaran IPA di Sekolah Dasar

Prima Magistra: Jurnal Ilmiah Kependidikan Volume 3, Nomor 1, Januari 2022, hal 131-138

mendukung kebersihan anak. Hal tersebut dapat dilihat dari konten yang tertera pada aplikasi.

Tabel 6. Hasil Validasi Ahli dan Praktisi

\begin{tabular}{llll}
\hline No. & Komponen & Score & Kategori \\
\hline 1 & Isi & 4,6 & Sangat Baik \\
2 & Penyajian & 4,75 & Sangat Baik \\
3 & Bahasa & 4,57 & Sangat Baik \\
4 & Kegrafikan & 4,75 & Sangat Baik \\
5 & Kesehatan & 5 & Sangat Baik \\
\hline \multicolumn{2}{l}{ Total } & $\mathbf{4 , 7 3}$ & Sangat Baik \\
\hline
\end{tabular}

Hasil dari angket kelayakan media dianalisis menggunakan standar baku ideal (Sbi). Hasil Sbi yang didapatkan sebesar 4,73. Hal tersebut menunjukkan bahwa media aplikasi "Ayo Cuci Tangan" dikategorikan layak digunakan untuk pembelajaran kelas 1 SD. Dari hasil validasi ahli materi, kedua validator menyatakan produk layak digunakan tanpa revisi.

\section{SIMPULAN DAN SARAN}

Telah dihasilkan media pembelajaran "Ayo Cuci Tangan" pada materi cuci tangan yang layak digunakan untuk pembelajaran di kelas $1 \mathrm{SD}$.

Perlu dilakukan penelitian lebih lanjut berupa penelitian eksperimen untuk membandingkan efektivitas penggunaan media konvensional dengan media aplikasi "Ayo Cuci Tangan" pada pembelajaran materi cuci tangan di tingkat SD. Perlu dilakukan pengembangan media aplikasi untuk mengatasi permasalahan dalam pembelajaran bagi siswa kelas $1 \mathrm{SD}$.

\section{DAFTAR PUSTAKA}

Amalia, R. N. (2019). PEMANFAATAN VIDEO MENCUCI TANGAN DALAM MENINGKATKAN MOTIVASI DAN PRAKTIK MENCUCI TANGAN PADA ANAK USIA SEKOLAH DASAR. JURNAL KEPERAWATAN, 10(1), 19-24. http://repository.akperykyjogja.ac.id/id/ eprint $/ 3$

Aminingsih, S. (2021). PENERAPAN METODE BERNYANYI UNTUK MENINGKATKAN KEMAMPUAN CUCI TANGAN PADA ANAK USIA SEKOLAH. KOSALA: Jurnal Ilmu
Kesehatan, 9(1).

https://doi.org/10.37831/kjik.v9i1.204

Andayani, R. (2016). Metode drill bermedia flash card untuk meningkatkan pengetahuan dan praktik cuci tangan pakai sabun pada anak Tunagrahita. JHE Journal of Health Education, 1(1), 37-43. https://journal.unnes.ac.id/sju/index.php /jhealthedu/article/view/9810

Andriani, Y., Suwarni, L., \& Arfan, I. (2020). Regional Language Mini Poster as an Alternative Media for Health Promotion Hand Hygiene . Jurnal Ilmiah Kesehatan, $\quad 2(1), \quad 9-18$. https://doi.org/10.36590/jika.v2i1.38

Azizah, N., \& Masithoh, A. R. (2018). SENAM CUCI TANGAN (HAND WASH) GURU PAUD AISYIYAH. Jurnal ABDIMAS Indonesia, 1(1).

https://ejr.stikesmuhkudus.ac.id/index.p hp/JAI/article/view/962

Azizah, N., Susanto, T., \& Susumaningrum, L. A. (2015). Pengaruh Terapi Bermain SCL (Snake, Cards, and Ladders) terhadap Keterampilan Mencuci Tangan Siswa Kelas I dan II di SDN Pakusari II Kabupaten Jember (The Effect of SCL (Snake, Cards, and Ladders) Games Therapy to Hand Washing Skill of First and Second G. Pustaka Kesehatan, 3(2), 295-302. http://jurnal.unej.ac.id/index.php/JPK/ar ticle/view/2613

Departemen Kesehatan. (2011). Pedoman Manajerial Pencegahan dan Pengendalian Infeksi Rumah Sakit dan Fasilitas Pelayanan Rumah Sakit dan fasilitas pelayanan Kesehatan Lainnya. Google Scholar

Desiyanto, F. A., \& Djannah, S. N. (2013). Efektivitas mencuci tangan menggunakan cairan pembersih tangan antiseptik (hand sanitizer) terhadap jumlah angka kuman. Kes Mas: Jurnal Fakultas Kesehatan Masyarakat Universitas Ahmad Daulan, 7(2), 24934. 
http://dx.doi.org/10.12928/kesmas.v7i2. 1041

Ashari, A. E., Ganing, A., \& Mappau, Z. (2020). Peningkatan Pengetahuan, Sikap dan Praktik Cuci Tangan Pakai Sabun pada Anak Kelas V Sekolah Dasar melalui Senam Cuci Tangan Pakai Sabun. Jurnal Ilmiah Permas: Jurnal Ilmiah STIKES Kendal,10(1), 11-18.

https://doi.org/https://doi.org/10.32583/ pskm.v10i1.635

Fadiah, T., Tirtayanti, S., \& Romiko, R. (2020). PENGARUH PELATIHAN CUCI TANGAN PAKAI SABUN (CTPS) DENGAN METODE AUDIOVISUAL TERHADAP PENGETAHUAN DAN KEMAMPUAN CUCI TANGAN DI SD NEGERI 95 PALEMBANG. Jukema (Jurnal Kesehatan Masyarakat Aceh), 6(1), 4953.

https://doi.org/10.37598/jukema.v6i1.8 00

Indrayani, E., Mutoharoh, S., \& Asti, A. D. (2019). METODE SENAM CUCI TANGAN MENURUT UNICEF PADA ANAK USIA PRASEKOLAH DI KECAMATAN PURING. The 9th University Research Colloqium (Urecol), 9(1).

http://eproceedings.umpwr.ac.id/index. php/urecol9/article/view/546

Juliawan, D. G., Mirayanti, N. K. A., \& Parwati, N. A. (2019). Pengaruh Pendidikan Kesehatan Dengan Bernyanyi Lagu Cuci Tangan Terhadap Tindakan Mencuci Tangan Anak Prasekolah. Journal Center of Research Publication in Midwifery and Nursing, 3(1), 11-20. https://doi.org/10.36474/caring.v3i1.12 4

Nurhidayati, A., \& Hilal, N. (2018). Pengaruh Pendidikan Kesehatan Tentang Phbs Dengan Media Permainan Ular Tangga Dan Ceramah Terhadap Pengetahuan Siswa Sd Negeri Limpakuwus Kabupaten Banyumas Tahun
2017. Buletin Keslingmas, 37(3), 332$338 . \quad$ https://ejournal.poltekkessmg.ac.id/ojs/index.php/keslingmas/arti cle/viewFile/3897/1029

Parasyanti, N. K. V., Yanti, N. L. G. P., \& Mastini, I. G. A. A. P. (2020). Pendidikan Kesehatan Cuci Tangan Pakai Sabun dengan Video Terhadap Kemampuan Cuci Tangan pada Siswa SD. Jurnal Akademika Baiturrahim Jambi, 9(1), 122-130. http://dx.doi.org/10.36565/jab.v9i1.197

Sari, A. P. (2021). Pengaruh Buzz Group Melalui Media Booklet dan Poster Terhadap Perilaku Cuci Tangan Pakai Sabun pada Siswa/I Kelas V SD IT Baitul Izzah Kota Bengkulu Era New Normal. Jurnal Promosi Kesehatan Poltekkes Bengkulu, 1(1). http://ojs.poltekkesbengkulu.ac.id/index .php/promkes/article/view/136

Rachmawati, F., Putri, H. A., \& Pujiastuti, T. W. (2015). Pengaruh Penyuluhan Tentang Cuci Tangan Dengan Media Video Terhadap Penerapanpraktik Cuci Tangan di SD Negerinogotirto Yogyakarta.Tugas Akhir. Google Scholar

Rahmawati, N. V., Utomo, D. T. P., \& Ahsanah, F. (2020). Fun handwashing sebagai upaya pencegahan covid-19 pada anak usia dini. Jurnal Masyarakat Mandiri, 4(2),

218. http://journal.ummat.ac.id/index.php/jm $\mathrm{m} /$ article/view/1958

Ridha, A., Selviana, S., \& Azzwar, F. (2016). Efektivitas media komik pada pengetahuan dan sikap mengenai cuci tangan pada siswa sekolah dasar. LINK, 12(1), 1-7. https://ejournal.poltekkessmg.ac.id/ojs/index.php/link/article/vie w/405

Risnawaty, G. (2016). Faktor determinan perilaku cuci tangan pakai sabun (CTPS) pada masyarakat di tanah kalikedinding. Jurnal Promkes: The Indonesian Journal of Health Promotion and Health Education, 4(1), 70-81. 
Muyassaroh, Reno Nurdiyanto, Laifa Rahmawati

Pengembangan Aplikasi Android 'Ayo Cuci Tangan' untuk Mengajarkan Kebersihan Anggota Tubuh pada Muatan Pelajaran IPA di Sekolah Dasar

Prima Magistra: Jurnal Ilmiah Kependidikan Volume 3, Nomor 1, Januari 2022, hal 131-138

http://dx.doi.org/10.20473/jpk.V4.I1.20 16.70-81

Saputri, A. A., \& Suryati, S. (2019). Pengaruh Pendidikan Kesehatan Menggunakan Audio-Visual Terhadap Pengetahuan Cuci Tangan Pakai Sabun (Ctps) Pada Anak Kelas Iv Di Mi Jamilurrahman Bantul. Medika Respati: Jurnal Ilmiah Kesehatan, 14(3), 245-254. https://doi.org/10.35842/mr.v14i3.231

Sutriyanto, K., Raksanagara, A. S., \& Wijaya, M. (2016). Pengaruh Permainan Kartu Kasugi terhadap Peningkatan Pengetahuan Perilaku Hidup Bersih dan Sehat pada Siswa. Jurnal Sistem Kesehatan, 1(4). https://doi.org/10.24198/jsk.v1i4.12828

Suwanti, I., \& Krisbiantoro, D. (2019). Pengaruh Pendidikan Kesehatan
Dengan Metode Bernyanyi Terhadap Perilaku Cuci Tangan Yang Benar. Jurnal Keperawatan dan Kebidanan, 11(2), 7-7. http://ejournal.lppmdianhusada.ac.id/index.php /jkk/article/view/34

Zurrahmi, Z. R., Hardianti, S., \& Syahasti, F. M. (2021). PKM PENGENALAN SENAM 6 LANGKAH CUCI TANGAN DAN SENAM IRAMA PADA SISWA KELAS 5 DAN 6 DI SDN 011 BUKIT KRATAI RUMBIO JAYA. COVIT (Community Service of Health), 1(2), 35-39. https://journal.universitaspahlawan.ac.i d/index.php/covit/article/view/2136 